\title{
Christmas Quiz, 1979
}

(For answers see p 1670)

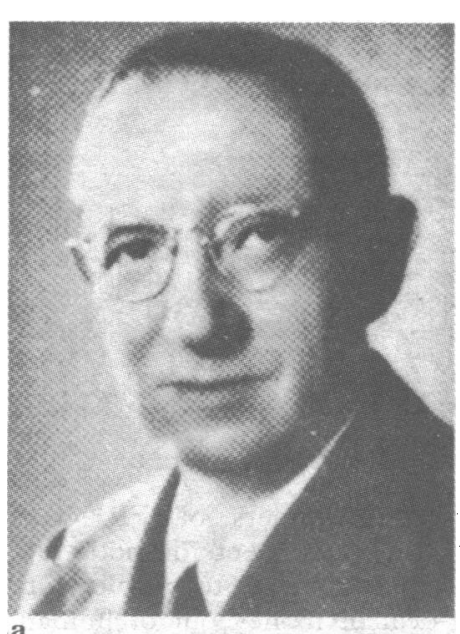

a

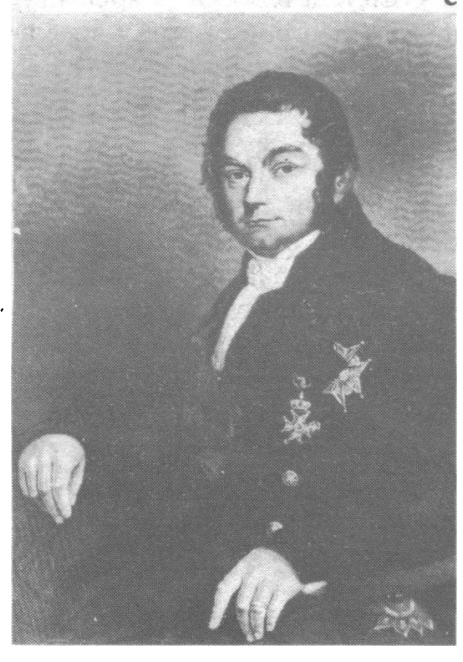

e

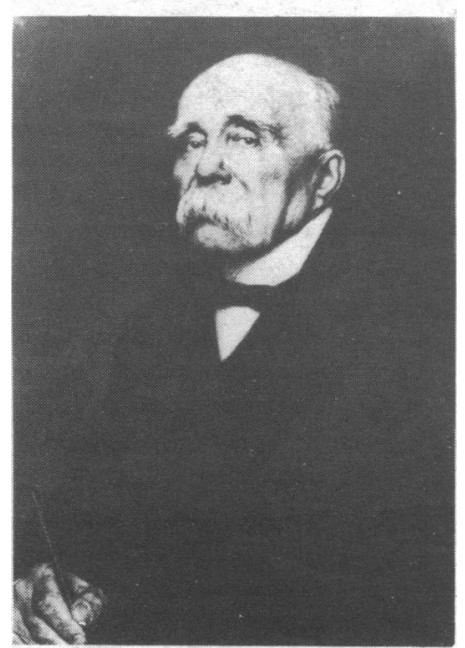

1. In which modern novels will you find the following? (a) A doctor whose poison kills the wrong man. Name the doctor and the poison.

(b) Two doctors who argue about the cause of cholera. What were their names and what happened to the doctor who decided to test his opponent's theory?

(c) A doctor who killed his wife with a drug said by the British Medical fournal to produce remarkable effects in relieving the uric-acid diathesis but to cause violent headaches. Name the doctor and the drug.

2. What are the following and, where appropriate, name their geographical origin?

(a) Chiclero's ulcer. (b) Danbury shakes. (c) Devonshire colic. (d) Derbyshire droop. (e) Halifax legs. ( $f$ ) Salem sarcoid. $(g)$ Da Nang lung. (h) Mal de Meleda.

\section{What are?}

(a) Human adjuvant disease. (b) Ataloia fever. (c) Frank's sign. $(d)$ Hot foot sign. (e) Autokabalesis. $(f)$ Shin splints. $(g)$ Jendrassik manoeuvre. (h) Jane Eyre syndrome.

4. See illustrations. Name the following whose anniversaries were celebrated in 1979.

(a) An American surgeon whose name commemorates a circulatory disease.

(b) A Viennese surgeon, a "failed" concert pianist and friend of Brahms, whose name is commemorated in an operation.

(c) A Swedish professor of medicine, better known as an inorganic chemist, who introduced the modern system of chemical nomenclature.

(d) A French pathologist who revolutionised the management of typhoid.

(e) A French doctor who achieved fame as a politician.

(f) A French surgeon who pioneered vascular surgery and had a syndrome named after him.

5. For what are the following patients remembered?

(a) Eliza Parachute. (b) Asmus Thomsen. (c) Mrs Mortimer. (d) Laetitia Napoleon. (e) Thomas McBean. (f) Joseph Dutton.

\section{What are?}

(a) Itai-itai disease. (b) Mahi-mahi flush. (c) Dum-dum fever. (d) Yo-yo walking. (e) Humpty-dumpty syndrome. $(f)$ Tweedledum-Tweedledee syndrome.

7. What are the following occupational diseases?

(a) Raspberry picker's dermatosis. (b) Covent Garden hummy. (c) Jeep driver's disease. (d) Billiard player's fingers. (e) Disco felon. $(f)$ Limbo dancer's bursa. ( $g$ ) Samaritan's anaemia.

8. What drugs or their effects are described by the following slang terms?

(a) Snappers (poppers). (b) Goon dust. (c) Ts and blues. (d) Angel dust and hot hog. (e) GAS. (f) Mad apple.

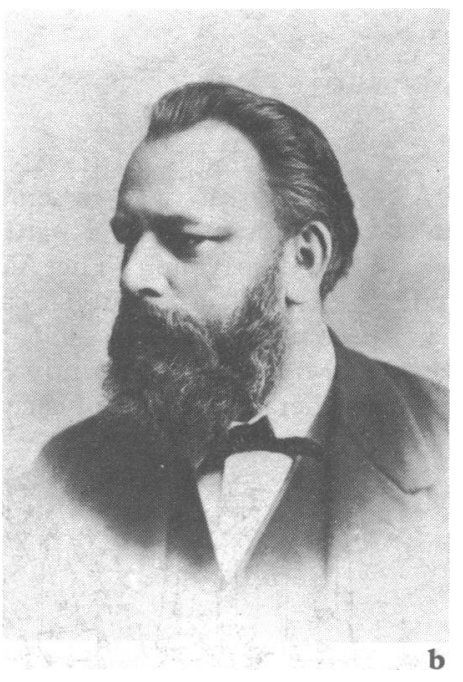
d
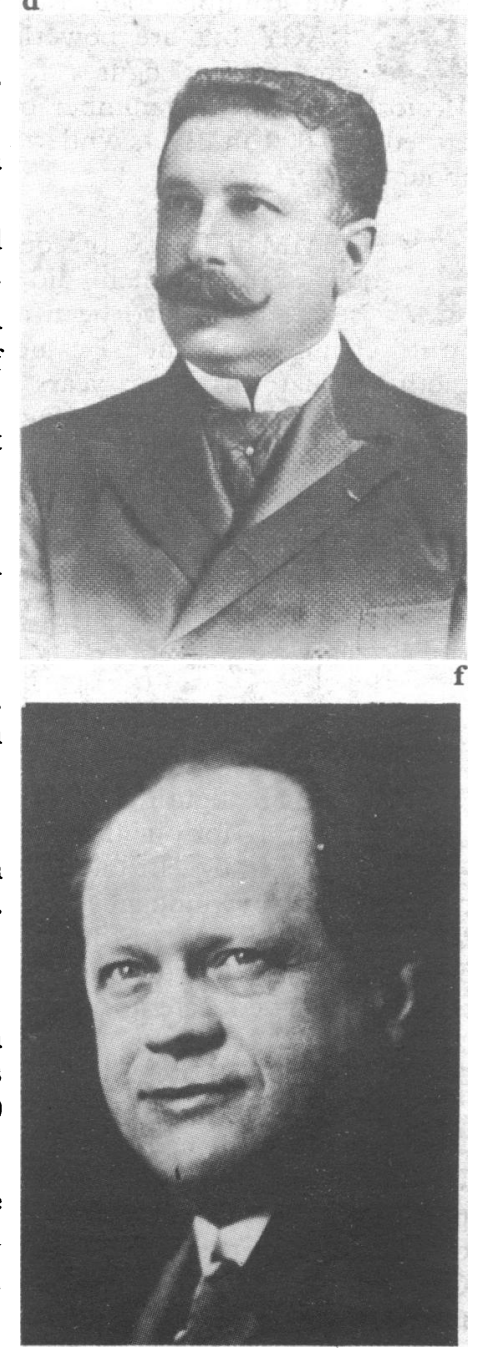
their burrows. I finally did discover from an ex-POW a trick that cut short the battles. I moved my bed out from the wall and stood each bed leg in paraffin (kerosene). Behind these moats I slept undisturbed, provided some guerillas hadn't camped out in the mattress.

\section{Other inhabitants}

The inhabitants of 67 Brook Green could be broadly grouped into three classes. First there were two other permanents. Joe was a tubercular Irish labourer whose week revolved around the dogs at the White City. The other was a retired captain who had pursued the unlikely combination of the Army and painting. He was not much of a painter but I understand he had become an "opinion" on the Florentines.

Then there were the medium-stay clientele. At first these were military or semi-military types. The most striking of these was a Canadian staff sergeant who used to supply Mrs Mac with both Scotch whisky and Canadian horse liniment for her chest. She would occasionally come to my room carrying a bottle of this stuff in one hand and the Sunday Express in the other and ask me to give her a rub. It really was great stuff; her chest went very red and we both inhaled a penetrating aroma of Super-Vick. I don't know what it did for her bronchial tubes, but my eyes and nose ran freely for hours.

In 1946-7 there was a steady supply of demob folk in London for "courses." The most memorable of these was a former petty officer in the Navy who ate steadily with a rhythmically clicking jaw, whose conversation was a steady tale of copulation. He was not particularly boastful but claimed that in a year at Portsmouth he got through four gross of French Letters which he had been given by a Yank PX man.

Later still came a succession of Indian doctors for postgraduate study. They were the forerunners of the flow that 20 years later provided much of the junior hospital manpower of the NHS. These first were very impressive. Most of them came from Lahore, soon to be part of Pakistan, but were Hindus. However there were also Sikhs and Muslims, and I wish I had been sufficiently mature to have listened carefully to their long civilised arguments about the future of the Indian subcontinent. I am afraid I was full of radical anti-imperialism and had no sensitivity to the agony that was taking place as Mountbatten negotiated the partition.

Then in the third category were the transients. Mostly these were musicians: members of the pit orchestra of touring opera companies doing a season at the Kings, or of a struggling dance band that had managed to make the Palais for the week. And sometimes there were singers or actors "resting" while trying to break into the West End. When the money ran out they went back to the provinces and I don't think any of them became famous.

Each year, however, we did have a visit that in its way was a bit of class. This would be occasioned by the Daily Herald Brass Band Contest at the Albert Hall and usually a few of the senior members of all of the top bands-Fairey Aviation or Fodens Motorworks would stay and the great Harry Mortimer would drop in and share a wee dram with Mrs Mac and the boys.

Mrs Mac was very sorry when I eventually moved into hospital but I went to see her regularly until I got married and we went to the States. I am afraid I didn't write to her much during our time in Baltimore and I received only one painfully written letter from her. On coming back to London we had a lot to do and although I phoned a few times, all I could gather from the foreign voices at the other end was that Mrs Mac no longer lived at 67. I managed to trace May, her niece in Camden Town, who told me Mrs Mac was in hospital in North London but would shortly be going into a "home" near her. I said I would wait till then and Diana and I would go and see her. This good intention was put off for several weeks and when I next called May she told me that Mrs Mac had relapsed a month before. She had been delighted to hear that "the doctor" was going to come and see her. May had tried to get hold of me but for one reason or another had failed. And Mac had died. I wish I had seen her once more. Or rather, I wish she had seen Diana and me because I was the closest she ever had to a son-and I felt a sort of responsibility to give her the pleasure of pride in us.

\section{CHRISTMAS QUIZ}

\section{Answers}

1. (a) The Human Factor by Graham Greene. Dr Emmanuel Percival. Aflatoxin.

(b) The Siege of Krishnapur by J A Farrell. Dr McNab and Dr Dunstaple. The latter believed that cholera was caused by impure air and died after drinking ricewater stools which Dr McNab maintained spread the disease.

(c) Malice Aforethought by Francis Iles. Dr Edmund Bickleigh. "Farralite" containing vanadium and gold.

2. (a) Chronic ulceration of ear in latex collectors in British Honduras. (b) Mercury poisoning among hatters in Danbury, Massachusetts. (c) Lead poisoning due to contamination of cider vats. (d) Impotence from pesticides. (e) Rickets in factory children in Yorkshire. $(f)$ Berylliosis from manufacture of fluorescent lights in Salem, Massachusetts. ( $g$ ) Respiratory failure during recovery from shock in Vietnam war. (h) Hereditary hyperkeratosis of palms and soles in inhabitants of island in Adriatic now called Mljet.

3. (a) Collagen and autoimmune diseases resulting from cosmetic surgery with silicone implants.

(b) Name suggested for indeterminate minor febrile illnesses-"Ah! there's a lot of it about."

(c) Diagonal ear-lobe crease said to be associated with coronary artery disease.

(d) A physical sign of retroperitoneal masses.

(e) Attempted suicide by jumping out of windows.

$(f)$ Stress fractures of tibia-a hazard of jogging.

(g) Reinforcement of tendon reflexes by clutching hands.

(h) Patients who have relatives of whom they are ashamed-for example, those with dementia or incontinence.

4. (a) Leo Buerger (1879-1943). (b) Theodor Billroth (1829-1894). (c) Johann Berzelius (1779-1848). (d) Fernand Widal (18621929). (e) Georges Clemenceau (18411929). $(f)$ René Leriche (1879-1955).

5. (a) An American Indian squaw, the first patient to be described with xanthomatous biliary cirrhosis, several years before the report of Addison and Gull.

(b) Suffered himself from myotonia congenita which he described.

(c) Jonathan Hutchinson described sarcoidosis as "Mrs Mortimer's malady."

(d) Precipitate labour, known in France as the Laetitia syndrome.

(e) The patient with multiple myeloma in whom Henry Bence Jones first found the characteristic proteinuria.

$(f)$ Died from relapsing fever (Dutton's fever) soon after discovering the tick carrier.

6. (a) Cadmium poisoning in Japan. (b) Flush named after native word for dolphin produced by eating scombroid fish. (c) Kala azar. (d) Caused by the pain of colic (e) Repeated falls and fractures. $(f)$ A form of folie à deux.

7. (a) Skin irritation due to an acarine mite. (b) Swelling on scalp in porters. (c) Prostatitis. (d) Paget's disease. ( $e$ ) Whitlow in disco addict produced by repeated finger snapping. $(f)$ Herniation of synovium of hip from acute extension in getting under bar. ( $g$ ) Anaemia from frequent removal of blood for investigations or transfusions.

8. (a) Amyl nitrite. (b) Substances containing stramonium like asthma cigarettes and Potter's asthma remedy.

(c) Pentazocine and pyribenzamine (tripelennamine). (d) Phencyclidine, which causes hyperthermia. (e) Ginseng abuse syndrome-hypertension, anxiety, insomnia, diarrhoea. $(f)$ Jimson seed which contains belladonna.

Photographs of Theodor Billroth, Johann Berzelius Fernand Widal, and Georges Clemenceau were supplied 